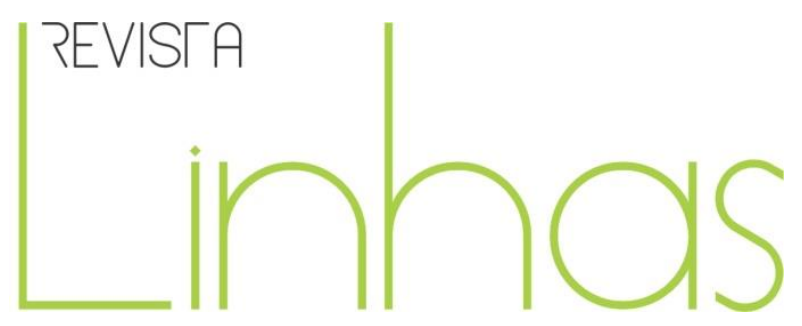

\title{
De la pantalla al aula: biopics de músicos y educación musical
}

\section{Resumen}

Son bastantes los films que a través de la fórmula del biopic (biographical motion picture) se aproximan a la vida y obra de compositores e intérpretes pertenecientes a la tradición clásica occidental. En este artículo revisamos algunas de sus características y proponemos su empleo en el aula, con el fin de pasar de su uso como simple elemento motivador a su aplicación para la mejora del aprendizaje y el desarrollo de la competencia cultural y artística. En lugar del visionado completo de estas cintas, recomendamos la selección de determinados fragmentos que conectan, además, con la estética del videoclip. El rigor histórico (más allá de los elementos ficcionales) con que directores como, entre otros, Gérard Corbiau, Jean-Louis Guillermou o Bernard Rose han tratado sus creaciones nos permite utilizar las mismas como herramientas interdisciplinares a través de las cuales nuestros alumnos (en el ámbito de la Educación Secundaria, pero igualmente extensible a otros niveles académicos) pueden comprender mejor los contextos de creación y recepción, ideologías, mercados y circuitos que acompañan/son la misma obra musical.

Palabras clave: Cine. Música. Biopic. Videoclip. Educación musical.

\section{Enrique Encabo}

Universidad de Murcia - Espanha enrique.encabo@um.es

\section{Para citar este artigo:}

ENCABO, Enrique. De la pantalla al aula: biopics de músicos y educación musical. Revista Linhas. Florianópolis, v. 21, n. 47, p. 223-239, set./dez. 2020. 


\section{From Screen to Classroom: Biopics and Music Education}

\begin{abstract}
There are several biopic films that focus on the life and work of historical composers and musicians belonging to the classical western tradition. In this article we review some of their characteristics and propose its educational employment, not only as a simple motivating element but as a tool to improve learning and to develop cultural and artistic competence. Instead of the complete viewing of these films, we recommend the selection of certain fragments that also connect with the aesthetics of the video clip. The historical rigor (beyond the fictional elements) with which directors such as Gérard Corbiau, Jean-Louis Guillermou or Bernard Rose, among others, have treated their creations, allows us to use them as interdisciplinary tools through which our students (specifically in Secondary Education but equally transferable to other academic levels) they can better understand the contexts of creation and reception, ideologies, markets and circuits that accompany / are intrinsic to the musical work.
\end{abstract}

Keywords: Cinema. Music. Biopic. Video clip. Music education.

\section{Da tela cinematográfica para a sala de aula: biografias de músicos e educação musical}

\section{Resumo}

São muitos os filmes que, através da fórmula biográfica (cinema biográfico), abordam a vida e a obra de compositores e intérpretes pertencentes à tradição clássica ocidental. Neste artigo revemos algumas das suas características e propomos a sua utilização em sala de aula, não apenas como simples elemento de motivação mas, sobretudo, para a melhoria da aprendizagem através do desenvolvimento de competências culturais e artísticas. Em vez da visualização completa dos filmes, recomendamos a seleção de alguns fragmentos que, se conectam com a estética do videoclipe. O rigor histórico (para além dos elementos ficcionais) com que realizadores como Gérard Corbiau, Jean-Louis Guillermou ou Bernard Rose trataram as suas criações, permite-nos utilizá-los como ferramentas pedagógicas interdisciplinares através das quais os nossos alunos (em âmbito do Ensino Secundário, mas igualmente extensível a outros níveis académicos) podem compreender melhor os contextos de criação e recepção, ideologias, mercados e circuitos que acompanham / são a mesma obra musical.

Palavras chave: Filmes. Música. Biopic. Videoclipe. Educação musical. 


\section{Introducción: cine y "nativos digitales"}

En las últimas décadas han aparecido varios e interesantes textos académicos que señalan las posibilidades y potencialidades del arte cinematográfico al servicio de la pedagogía, cualquiera que sea la disciplina a conocer por parte de los educandos (FLORES AUÑÓN, 1982; HUESO, 1998; MONTOYA RUBIO, 2010, entre otros). Hoy por hoy el lenguaje audiovisual adquiere, a través de la expresión simbólica, un valor per se como producto cultural resultante de las manifestaciones humanas, especialmente sensible para los niños y jóvenes, acostumbrados a generar nuevos signos de expresión más allá de la palabra. En el siglo XXI es evidente que debemos adecuar los materiales educativos a la cultura inmediata de nuestros alumnos, "su” cultura; los principios del aprendizaje significativo así lo señalan, al igual que el poderoso atractivo que lo multimedia posee para los adolescentes. No obstante, no podemos perder de vista que esta adecuación pasa inevitablemente por dos características fundamentales que dominan la sociedad y el conocimiento en la actualidad: por un lado, nos encontramos inmersos en la llamada sociedad 2.0 (ENCABO, 2017) y, por otro, y en directa conexión con este aspecto, para algunos autores la nuestra es también la era del entretenimiento.

En cuanto a la primera característica, diversos estudios han analizado el impacto de la misma en la cultura, destacando los publicados por Prensky (2001), quien caracterizó a las nuevas generaciones como "nativos digitales". La cultura digital configura la forma de ver y aprehender la realidad por parte de los jóvenes (y no tan jóvenes) con un notable impacto en la educación, la comunicación, el consumo y el ocio, que pueden y deben ser estudiados desde los campos sociológico, antropológico, artístico, científico y educativo.

No tiene sentido pensar que los adolescentes, solo por conocer y estar en contacto permanente con la tecnología, obtienen todo el rendimiento y hacen un uso adecuado de la misma. No nos referimos únicamente a los peligros evidentes que un mal empleo de las redes sociales conlleva (referido a la exposición inconsciente y reveladora de aspectos íntimos y personales), sino especialmente a no explorar, permaneciendo en niveles de gratificación y deleite inmediatos, las infinitas posibilidades que la cultura audiovisual ofrece: cierto que hoy, más que nunca, el mundo está en una pantalla -que incluso viaja en 
nuestro bolsillo a través de los smartphones- pero esta experiencia casi universal puede convertirse en una experiencia mínima, local y pobre, si no existe la curiosidad y el deseo por conocer y explorar otros mundos y manifestaciones culturales. El debate, obviamente, no se encuentra en los términos tecnología sí/tecnología no ${ }^{1}$ o mundo adulto/mundo joven, sino que es necesario un dialogo entre analógico/digital, joven/adulto, local/universal.

Atendiendo a la segunda característica que advertimos, probablemente cuando Neil Postman (1991) señaló las características de la sociedad del entretenimiento no sospechaba que estas se verían notablemente incrementadas con el advenimiento de la sociedad 2.0. La inmediatez en el mensaje, la ausencia de detenimiento en el mismo y el consumo rápido de novedades forman parte de la cultura juvenil; los mecanismos de recepción han cambiado, al igual que los de producción -no podemos olvidar que los jóvenes, más que consumidores, son prosumidores (STRANK, 2014), reinterpretando y reelaborando los productos culturales a través de aplicaciones, plataformas y redes sociales como Twitter, Instagram, TikTok o Youtube- y no podemos achacar a falta de interés o concentración lo que, en realidad, es una nueva forma de acceder y conocer el mundo. En este sentido, no deja de resultar infructuoso el debate en torno a los niveles de atención de los denominados "millennials" (FERRER, 2010); la sociedad del siglo XXI en su conjunto, caracterizada por la velocidad y la búsqueda constante de novedades, es la sociedad, a un nivel estético, de lo anecdótico frente a lo sublime (BOZAL, 1999). Que nuestros alumnos comprendan el valor del arte, atiendan y entiendan el mismo, es un proceso educativo que, sin perder de vista estas premisas, depende directamente de nosotros.

\footnotetext{
${ }^{1}$ En demasiadas ocasiones se ha incidido únicamente, en una suerte de reduccionismo, en el papel positivo o negativo de la tecnología: "[...] la tecnología no es, de todos modos, la clave del cambio musical. Otras fuerzas sociales y políticas son más significativas en el cambio de nuestra manera de concebir la música y en la determinación de cómo la propia tecnología es comprendida" (FRITH, 1999, 22).
} 


\section{Biopics de músicos: casi una historia del cine y de la música}

Pretender realizar un recorrido por todas las películas que han empleado con mayor o menor acierto o con mayor o menor énfasis las vidas de músicos célebres al servicio del discurso cinematográfico es una tarea titánica que dista mucho de los objetivos que perseguimos en este breve texto. Desde casi los albores de la industria cinematográfica esta persiguió reflejar las azarosas vidas de músicos y artistas atendiendo a sus aspectos más románticos y legendarios; no está de más recordar, aunque no forma parte del corpus de películas que nos ocupan, que la que es considerada primera película sonora, The Jazz Singer (Alan Crosland, 1927) tiene como protagonista precisamente a un músico². No obstante, es posible observar un aumento de este tipo de cinematografía en décadas recientes, pudiendo establecer como referencia -tanto por el año de estreno como por el cuidado en la producción y el éxito en taquilla- la cinta dirigida por Milos Forman Amadeus $(1984)^{3}$.

A la hora de acercarnos a estos materiales podemos establecer una suerte de categorización de los mismos (una clasificación que en absoluto pretende definir o encasillar, sino comprender e identificar) según: 1) reflejan la vida y avatares de músicos y artistas como inspiración, sin ni siquiera atribuir el verdadero nombre a los protagonistas de la trama 2) la convulsa biografía de los personajes históricos reflejados es protagonista del film, pasando su obra artística a un segundo plano 3) existe una intencionalidad por, a través de la vida y obra del artista, reflejar una época pretérita mediante una cuidada documentación y ambientación histórica.

Atendiendo a las características de nuestro estudio es obvio que el tipo de films que más nos interesan son estos últimos, aunque no debemos obviar la importancia y

\footnotetext{
${ }^{2}$ El nacimiento y desarrollo del cine coincide cronológicamente con los años dorados del jazz; por esta razón es lógico que los primeros biopics musicales se centren en artistas vinculados de uno u otro modo a esta música. Posteriormente, con la eclosión del rock'n'roll y la cultura juvenil, y la conversión del lado salvaje de la vida en sinónimo de romántica rebeldía y en icono pop, las miradas cinematográficas recrearán las vidas de artistas provenientes de otros universos (SALVÁ, 2008, 178). En este estudio atendemos únicamente a los biopics de músicos pertenecientes a la denominada música "culta" occidental, aunque los aspectos que estudiamos pueden ser de utilidad para la aproximación a otros géneros.

${ }^{3}$ El biopic de Milos Forman pasará a formar parte de la cultura popular, como podemos observar en posteriores alusiones más o menos explícitas al film en productos enormemente populares como The Simpsons (en el episodio "Margical History Tour", undécimo episodio de la temporada número quince) o How I met your mother (segundo episodio de la cuarta temporada).
} 
empleabilidad de los anteriores. Respecto al primer grupo, un caso paradigmático es The Red Shoes (Michael Powell y Emeric Pressburger, 1948), cinta en la que en ningún momento se alude a los Ballets Russes de Diaguilev, pero en la que la huella de los mismos es más que notable. Desde la figura tiránica del director de la compañía o el reconocimiento de programas de mano (mostrados en el film) que perfectamente podrían corresponder a la legendaria troupe hasta, lo que es mucho más interesante, la creación del ballet que da nombre a la película británica, donde queda de manifiesto la fecunda e intensa colaboración de coreógrafos, escenógrafos, compositores... unos cinematográficos Boris Lermontov, Julian Craster, Grisha Ljubov y Vicky Page, trasunto de los Sergei Diaguilev, Igor Stravinsky, Michel Fokine y Vaslav Nijinsky de principios del siglo XX (ENCABO, 2015).

El segundo grupo de películas a las que nos referimos es difícil de acotar por cuanto determinar cuánto peso tiene la biografía y cuánto la obra artística es, inevitablemente, un acto subjetivo. A pesar de este obstáculo, es evidente que nos referimos a films como The Music Lovers (Ken Russell, 1971), Nijinsky (Herbert Ross, 1980) o Inmortal Beloved (Bernard Rose, 1994). Aunque lo que parece primar en estas películas es el aspecto biográfico y las posibilidades narrativas del mismo, los momentos musicales ${ }^{4}$ nos ofrecen, como más tarde detallaremos, muchas posibilidades en nuestra acción educativa.

El último grupo, que también lo es cronológicamente, es el que pretende reconstruir una época a partir de una figura (acaso una excusa) musical. Destaca sobremanera la figura del director belga Gérard Corbiau, pero también la de otros cineastas como Bernard Rose o Jean-Louis Guillermou. Si bien puede haber quien critique estas cintas atendiendo al rigor histórico o la exactitud de los datos, nadie puede negar que en ellas existe una voluntad historiográfica ${ }^{5}$, que, por supuesto, pasa por la mirada artística y la relectura de un director. No hay que olvidar que no estamos ante documentales, sino ante películas, y los directores

\footnotetext{
${ }^{4}$ Aunque estos films están repletos de música extradiegética de gran interés, para nuestro estudio nos centramos únicamente en las músicas que suenan de manera diegética y que, de este modo, se inscriben en la narrativa audiovisual.

${ }^{5}$ Recreación histórica que muchas de las producciones operísticas y de ballet de la actualidad han, muy conscientemente, olvidado. En este sentido, estas cintas nos ofrecen una posibilidad más, pues las nuevas propuestas escénicas en torno a la danza y la ópera distan de una pretendida reconstrucción histórica, releyendo en clave contemporánea las producciones y, por tanto, alejándose de la estética (fenómeno especialmente llamativo en el repertorio barroco) en la que estas obras ven la luz.
} 
no son documentalistas, sino creadores cinematográficos con una mirada y una intencionalidad artística. Visionando estos films comprendemos que a través de ellos asistimos a la recreación histórica de una época (mediante un cuidado decorado, vestuario, caracterización, música -obvio-y gesto) aspecto que consideramos puede ser de utilidad en el ámbito de la educación musical.

\section{De la pantalla al aula}

Todos los ejemplos anteriormente reseñados son magníficas obras de arte. Ahora bien, ¿cómo emplearlos en nuestras aulas? No parece un modo muy adecuado el propiciar el visionado (en el aula o en casa) de los films completos; en nuestro recuerdo conservamos la recomendación de ver, a una edad quizá demasiado temprana, Amadeus: lejos de provocar el efecto deseado, el visionado íntegro de la película, aun con sus maravillosas virtudes, para una audiencia joven y acostumbrada a otro ritmo de montaje, puede ser contraproducente.

En general los films referenciados resultan enormemente estimulantes para una audiencia con un bagaje cultural amplio, por cuanto se encuentran en ellos numerosos matices dignos de ser leídos e interpretados; no obstante, y poniéndonos en la piel de nuestros alumnos (que no tienen, ni tienen por qué tener un bagaje que se asume a lo largo de los años por múltiples vías), el ritmo de estas cintas puede resultar lento y fatigante.

¿Cuál es entonces la utilidad existente en las mismas? Tratamos de responder esta pregunta conectando las obras artísticas que analizamos con la cultura a la que pertenecen nuestros alumnos (y acaso también todos nosotros). Hemos destacado al inicio dos aspectos de la misma: su conexión directa con el universo audiovisual (y obviamente el cine, que aunque con una larga trayectoria sigue siendo la más joven de las siete artes, responde a esta característica) y su adscripción a la cultura del entretenimiento, regida por las leyes de la inmediatez, la velocidad y la sencillez del mensaje.

Si pensamos por un momento estas características no es difícil adivinar que se corresponden con las propias del videoclip. Atendiendo a algunos aspectos definitorios del 
videoclip $^{6}$-obviamos en este caso su característica comercial o publicitaria pues nos Ilevaría a un debate más amplio del que nos ocupa, y que atañe a la música, la televisión o el cine en tanto industrias culturales- comprendemos que se trata de una forma de arte dinámico en la que lo visual y lo musical se combinan, logrando un efecto único que sería imposible sin la interacción entre ambas partes (SEDEÑO VALDELLÓS, 2009). El videoclip resulta enormemente atractivo porque, precisamente por su característica audiovisual, genera experiencias que sintetizan lo inteligible y lo sensible, lo racional y lo emotivo. La imagen -sonora- en movimiento genera unos discursos que potencian el aprendizaje de cualquier naturaleza, y que no puede ser ignorado por los profesionales de la educación.

No podemos atribuir estas características a las películas que tratamos -aunque en realidad el biopic y el videoclip comparten un aspecto fundamental, esto es, la narración a partir de la fragmentación7-, pero sí a determinados fragmentos dentro de los mismos. De hecho, todos los que a continuación observaremos implican la paralización de la narración, y aunque respetan el principio de continuidad de las películas (aparecen de manera coherente), la filmación íntegra de los fragmentos musicales sitúan estas "minipelículas" dentro de los largometrajes cerca de las características de los videoclips, según la clasificación de Sedeño Valdellós, de tipo descriptivo-narrativo.

Un caso ilustrativo de lo señalado nos lo ofrece, desde la figura del propio cineasta, el film The Devil's Violinist (2013). La película está realizada por Bernard Rose, autor

\footnotetext{
${ }^{6}$ Son muchos los autores (TAGG, 1995, SEDEÑO, 2002, VIÑUELA, 2013, entre otros) que han estudiado el videoclip como formato. Eduardo Viñuela afirma que el video musical es un fenómeno audiovisual que no cuenta con una definición válida y consensuada que lo delimite y lo sitúe dentro de los fenómenos que conforman la industria musical $(2003,539)$, señalando entre las dificultades para la definición del mismo los cambios derivados de la evolución de la tecnología de la imagen, las innovaciones en la música popular, los distintos canales de distribución, y la diversificación del consumo a causa de la aparición de nuevos contextos. En el mismo texto el autor discute las relaciones entre cine y videoclip. En nuestro estudio obviamos esta discusión pues, en el caso que nos ocupa, música e imagen tienen la misma importancia y comparten protagonismo en la narración.

7 Si la base del videoclip es el relato fragmentado, también lo es del biopic, donde a pesar de la pretendida coherencia se escogen determinados fragmentos de vida (recreada, imaginada o inventada) para construir la historia. Bajo la apariencia de narración lineal, en realidad un biopic es una sucesión de fragmentos, una concatenación de sucesos a los que el espectador otorga continuidad: "[... ] muchos acontecimientos son dotados de mayor dramatismo, el tiempo es condensado para que todos los highlights de una vida quepan en dos horas [...] a veces varias personas son convertidas en una sola. Muchos hechos se inventan de mala manera. $Y$ todo con el fin de dotar la vida recreada de un arco narrativo y dramático satisfactorio" (SALVÁ, 2008, 176).
} 
igualmente de Inmortal Beloved (1994) y, lo que resulta más interesante, director con anterioridad a su carrera cinematográfica de videoclips como Red Red Wine (UB40, 1983) o Relax (Frankie goes to Hollywood, 1984). En el caso del film protagonizado por David Garrett, las influencias de la estética del videoclip son más que evidentes.

Si atendemos, por ejemplo, al fragmento en el que Paganini/Garrett interpreta el Caprice 24 comprendemos que el tratamiento que se da al histórico violinista es el de una estrella de la música pop/rock: el movimiento de la cámara, la iluminación, el público de la sala (a la manera de extras), la historia de amor condensada en la imagen de la figura femenina y, especialmente, el protagonismo absoluto del intérprete ${ }^{8}$ que, con una imagen similar a la de los ídolos de la industria musical actual, nos recuerda el carácter de genio del virtuoso romántico (Plantinga, 1992, 190 y ss.), capaz de provocar pasión y desmayos a través de su arte y su figura -no está de más subrayar que la época de Liszt, Chopin y Paganini es la época del auge económico de la burguesía, con el correspondiente incremento del mercado musical a través de la apertura de nuevas salas de conciertos.

En el caso de The Devil's Violinist las similitudes entre una estética y otra, entre la figura del intérprete legendario y la estrella musical de nuestra contemporaneidad son muy notables. En otros no lo son tanto, por distancia cultural o cronológica; aún así, es posible hallar varias de estas características en películas como Farinelli (Il castrato) (1994) o Le roi danse (2000).

Farinelli (Il castrato) se basa en la vida del célebre Carlo Broschi, castrato cuya popularidad le llevó incluso a ganar el favor del rey Felipe V. Aun con todas las licencias ficcionales que Gerard Corbiau se permite, tanto la ambientación como las escenas musicales ${ }^{9}$ merecen especial mención por el esmero en la reconstrucción histórica. Así el

\footnotetext{
${ }^{8}$ David Garret, protagonista del film, es una de esas "estrellas" de la música clásica actual que en su imagen y los canales de circulación de su música es igual a las estrellas del pop/rock. Su canal de Youtube tiene más de un millón de suscriptores, y alguno de sus videos, como su interpretación del tema de Coldplay Viva la Vida, cuentan con más de 95 millones de reproducciones.

9 Si cuidada fue la producción del film, no lo fue menos la banda sonora, a cargo del director y clavecinista Christophe Rousset y la agrupación Les Talens Lyriques. Para conseguir el peculiar timbre del castrato se mezclaron dos voces (la de la soprano Ewa Malas-Goldewska y la del contratenor Derek Lee Ragin) en los laboratorios de L'Institut de recherche et coordination acoustique/musique (IRCAM). La banda sonora de esta película nos permite además apuntar otro aspecto, y es la relación y colaboración de los estudios cinematográficos con los sellos discográficos, permitiendo, a partir del estreno de la película, la difusión de
} 
fragmento en que Carlo Broschi interpreta el aria da capo “Ombra fedele anch'io" (de la ópera Idaspe, compuesta por Riccardo Broschi), a través del cual es posible comprender muchas de las características de la ópera barroca: la admiración hacia los castrati -documentada ya en su momento- mostrada a través de los suspiros y el delirio de las asistentes; la importancia atribuida a la escenografía, atrezzo y la maquinaría escénica; la disposición de los teatros; el artificio en maquillajes y pelucas o el protagonismo absoluto del divo.

Sin abandonar el barroco, aunque trasladándonos a Francia, Le roi danse posibilita comprender las implicaciones políticas del arte de la danza en la figura del Rey Sol: a través del fragmento fílmico en el que se ofrece parte de la representación del Ballet de la Nuit, Corbiau muestra mediante los diálogos -ofrecidos al tiempo que la música de Lully- las estrategias y maquinaciones políticas reflejadas en la coreografía, y no únicamente. Otros muchos aspectos son ofrecidos por el realizador belga en menos de cuatro minutos: la innovación de los tacones para el baile, la técnica dancística del momento (diferente por completo al ballet romántico, con mayor protagonismo de las danzas bajas y del gesto y el mimo) y la situación de los artistas (músicos, dramaturgos...) en la Corte de Versalles. Esta capacidad de síntesis unida al lenguaje audiovisual posibilita que podamos mostrar a nuestros alumnos de una manera directa y amena muchos de los aspectos de la danza barroca: “[... ] el testimonio acerca del pasado que ofrecen las imágenes es realmente valioso, complementando y corroborando el de los documentos escritos. Muestran ciertos aspectos del pasado a los que otros tipos de fuentes no llegan" (BURKE, 2005, 201).

A propósito de la relación entre los artistas, esta tiene un carácter protagonista en el film de Herbert Ross Nijinsky (1980). En él encontramos fragmentos correspondientes a representaciones de los Ballets Russes que pueden ser empleados como piezas artísticas desprendidas de la película. Así la recreación de la representación del Prélude à l'après-midi d'un faune o, especialmente, de La Sacre du Printemps. Durante demasiado tiempo hemos cometido el error de hablar del "gran escándalo" que supuso este estreno atendiendo únicamente a la música de Stravinsky y olvidando el aspecto escénico; sin este es imposible

la banda sonora de la misma. Un caso paradigmático lo constituye el film Tous les matins du monde (Alain Corneau, 1991) cuya banda sonora fue un sonado éxito de ventas. 
comprender lo sucedido en el Théâtre des Champs-Élysées en 1913. El extrañamiento provocado por esta nueva estética (en lo musical pero igualmente en lo coreográfico y estético), la dificultad coreográfica (con un Nijinsky fuera de sí contando los pasos desde bambalinas gracias a los aprendizajes obtenidos de Marie Rambert), el "ruido" del foso y de platea... todo ello se nos ofrece en esta cinta condensado de forma magistral, pudiendo nuestros alumnos, a través de este visionado, entender realmente lo que sucedió en aquella histórica noche de mayo en París.

Hemos hablado únicamente de algunos fragmentos y la elección no ha sido azarosa. Muchos de ellos se encuentran, como piezas desprendidas de los films originales, en Youtube y otras plataformas de streaming, difuminando nuevamente las fronteras entre el videoclip y el biopic cinematográfico. No sabemos si los directores de las cintas analizadas tenían, consciente o inconscientemente, esta intención al realizar el montaje de sus obras, pero lo cierto es que estos fragmentos constituyen una obra artística, con una intencionalidad y un mensaje $\mathrm{y}$, por tanto, podemos emplearlos como ilustración audiovisual para comprender estilos musicales de épocas pretéritas. Y aún más: Youtube, además de ofrecer un acceso directo sin intermediarios, en cualquier momento y lugar a estos materiales, incorpora la característica Related Videos, a través de la cual los jóvenes, animados a visionar estos fragmentos, pueden acercarse a otras expresiones artísticas cercanas y sentir curiosidad por las mismas. Es sabido que los más recientes intérpretes de la llamada música clásica o docta han incorporado muchos de los procedimientos del mercado musical pop/rock, y ello es evidente en artistas como Vanessa Mae, David Garret, Cecilia Bartoli y Yo Yo Ma, entre otros ${ }^{10}$. Por tanto, animando a nuestros alumnos a visionar estos fragmentos cinematográficos, los animamos a acceder a un universo de universos, a

\footnotetext{
${ }^{10}$ Un fenómeno especialmente llamativo en la denominada Early Music (incluyendo en esta etiqueta también la música barroca), como acertadamente han estudiado Úrsula San Cristóbal y Rubén López Cano (2013): “In recent years the dissemination of Western Art Music by means of audiovisual media has been intensified, and its presence is remarkable in social networks like YouTube and Vimeo. The Western Art Music, specially the early music, is searching its place in the current audiovisual space. Visual strategies include, among others, techniques of the art films, advertising, fictional short films, and popular music videos". San Cristóbal y López Cano ofrecen un interesante recorrido analizando diversos videoclips; a estos videoclips podríamos unir los fragmentos fílmicos que señalamos pues, aunque no son concebidos originalmente en este formato, en el nivel del consumidor pueden funcionar como tal.
} 
una nube de conocimiento a través de la cual sentir curiosidad, sorpresa y, por supuesto, llevar a cabo de manera autónoma su propio aprendizaje.

\section{Entre la performatividad y la sinestesia}

Acercar a nuestros alumnos a épocas pretéritas de la historia de la música no es una tarea sencilla. El principal problema es que sean capaces de dotar de significado a estos materiales, pues en nuestra contemporaneidad se nos presentan descontextualizados (COOK, 2001; SMALL, 1989) y parece más una obligación que un placer apreciar estas músicas al no comprender los contextos de interpretación, recepción y circulación que les dieron origen y sentido. A través de estos films podemos mostrar a nuestros jóvenes que estos contextos no son tan alejados ni distintos a los de hoy en día: los castrati barrocos o los virtuosos románticos son el correlato -con sus semejanzas, pero también con sus múltiples diferencias- de las estrellas pop actuales, y la fascinación y entusiasmo que generaron son equiparables a la que los ídolos de nuestros alumnos les hacen sentir y experimentar.

No obstante estas virtudes, alguien podría preguntarse ¿es adecuado o "lícito" enseñar la historia de la música de esta manera? Si atendemos al concepto de performatividad es obvio que el respeto a la obra original o al autor, e incluso al medio, queda en entredicho. Los fragmentos seleccionados pueden ser considerados dentro del universo de la performance musical, pues no dejan de ser unas prácticas audio-músicovisuales producidas y difundidas a través, en este caso, de un medio audiovisual. No estamos ante un testimonio, ni un documental y ni siquiera su propósito es venerar la obra o el artista; estamos ante un nuevo artefacto cultural, cinematográfico y musical, que solo puede existir en la realidad del soporte audiovisual y que genera sus propios mecanismos de recepción e interacción.

Por otra parte, comprendemos que al poner sobre la mesa la relectura y el universo transmedia no hablamos sino de sinestesias. Las sinestesias tuvieron especial fortuna en el romanticismo y, fundamentalmente, en la segunda mitad del siglo XIX a partir del simbolismo. Cuando el concepto fue acuñado y empleado aún el cine no existía, pero es 
fácil observar que nos movemos en un mismo universo en el que a través de los trasvases artísticos unas obras y otras se influyen, nutren y enriquecen. En el caso que nos ocupa, la música y la historia dan origen al producto cinematográfico, pero este a su vez dota de un nuevo significado a obras que, de otro modo, serían transmitidas a través de otros canales ( $\sin$ la riqueza que el contexto audiovisual proporciona) o sencillamente invisibles para una gran parte de las audiencias.

No se trata de buscar "la verdad" (lo que quiera que signifique esta palabra) sino la experiencia. Una experiencia estética multisensorial, en la que la politextualidad consciente permite ver/escuchar una obra de arte que es, simultáneamente, muchas obras de arte. A través de estos materiales artísticos olvidamos, siquiera por un instante, esa inexpresiva historia de "hombres blancos muertos" para acercar a nuestros alumnos, convenientemente guiados, a una experiencia más inmediata a través de un lenguaje más cercano; un lenguaje más sintético que analítico, denotativo y connotativo, concreto y de fácil acceso por su carácter representativo -no conceptual o abstracto, independientemente de los múltiples mensajes que puedan desprenderse del mismo-y en el que predomina la emotividad y el impacto; un lenguaje en el que "sentir" es “comprender”.

\section{Conclusiones}

En el pasado algunos docentes incluían, tratando de aumentar el interés de los alumnos por la historia de la música docta, anécdotas referidas a la biografía de los compositores y artistas que protagonizan la misma. Hoy en día puede resultar mucho más motivador, al explicar las biografías de Beethoven o Vivaldi, más que una lectura o una explicación, visionar la escena de la representación de la Novena Sinfonía en Inmortal Beloved (1994) o los títulos iniciales de Antonio Vivaldi, un prince à Venise (Jean-Louis Guillermou, 2000). Son varias las razones que nos permiten afirmar la empleabilidad de los biopics basados en figuras históricas de la música culta en la enseñanza musical.

Las diferentes visiones que diversos cineastas han ofrecido de las vidas de músicos y compositores proporcionan numerosos matices que nos permiten, a través de un arte 
cercano en el tiempo, acercarnos y comprender otro más lejano cronológicamente. Proponemos aprovechar estos recursos teniendo presente la cultura de nuestros alumnos, una cultura digital y que responde a las características de la era del entretenimiento. Es por esta razón que no entendemos el aprovechamiento didáctico de estos materiales a través de su visionado completo, sino de fragmentos desprendidos que tienen significados que, además, pueden ser ampliados por el profesor. En este sentido, los films que hemos analizados no suponen ningún problema pues podría pensarse que los directores, en el montaje, tenían presente, consciente o inconscientemente, la estética del videoclip. Hablamos, por tanto, de pequeñas obras artísticas dentro de otras obras artísticas, una estructura en abismo que nos lleva del cine a la música, de esta a la historia, y, a través de la recreación histórica, a la comprensión de las artes mayores y menores de épocas pretéritas, un todo que vuelve a unirse en un producto cultural que, ofrecido de forma conveniente, estimula la curiosidad de nuestros alumnos, propiciando un aprendizaje realmente significativo.

Por otra parte, los canales de circulación de estos fragmentos corroboran nuestra idea. Encontrar fragmentos de estas películas en Youtube es sencillo, lo cual demuestra su estética videoclip (duración en torno a cuatro minutos, montaje atractivo, ritmo rápido centrado en la figura del protagonista/estrella, mensaje directo y sencillo de entender... ) y además propicia que podamos promover e incentivar en nuestros alumnos la búsqueda en los mismos canales de otras piezas artísticas, cinematográficas o no, pues la estética asumida por las nuevas propuestas de intérpretes y directores de música antigua, barroca y romántica, entran dentro de este universo transmedia.

Lejos de criticar o buscar criterios basados en el rigor histórico en estas obras podemos entender que suponen un acercamiento a la obra mucho más vivo que leer en libros las características histórico-artísticas del momento o escuchar las obras musicales por otros medios no visuales (aunque estas diferentes formas de acceso a la información son, en cualquier caso, complementarias). Comprender una creación artística a partir de otra creación artística, seguramente parcial y condicionada por la visión del director, pero rica en matices e interpretaciones. Una expresión artística más cercana al modo en que nuestros alumnos aprehenden la realidad. No obstante, no se trata de recibir estas 
propuestas como realidades inmutables, sino de aprovechar aquello que nos ofrecen frente a otro tipo de artefactos culturales: una experiencia polisensorial donde vestuario, iluminación, gesto, caracterización, ambientación... están al servicio del reflejo de una época histórica (reflejo condicionado por la visión del director, pero reflejo a fin de cuentas) que de este modo puede ser vivida de manera mucho más directa por los alumnos. Este empleo no sustituye otros materiales ni otros enfoques; aumenta y enriquece. No supone una recepción pasiva en la que un creador "habla” y otros “escuchan”; mediante la acción indispensable del docente, el receptor interactúa con el producto cultural, analiza, critica y decodifica la obra ofrecida. Si no posee los mecanismos para llegar al significado que el significante ofrece, se ve obligado a buscarlos. Aquí radica la riqueza de estas nuevas posibilidades educativas.

La interdisciplinariedad, sinestesias, polisensorialidad, transmedia, multiplicidad de lenguajes artísticos... que han caracterizado lo hasta ahora escrito, favorecen la competencia cultural y artística de nuestros alumnos pues, al pretender acercarlos a una expresión artística, lo hacemos a través de otra con valor en sí misma. Obras artísticas que nacen a partir de otras y dialogan y se enriquecen y enriquecen a las anteriores. Cine, teatro, música, danza, pintura... vuelven a unirse proporcionándonos la posibilidad de ofrecer unos productos culturales a nuestros alumnos, en conexión directa con su tiempo, que remiten a otros que, convenientemente interpretados, actualizados y releídos, favorecen, sin ningún género de duda, su formación integral. A fin de cuentas, al -hacia el-arte por el arte.

\section{Referencias}

BOZAL, Valeriano. Necesidad de la ironía. Madrid: Visor, La balsa de la Medusa, 1999.

BURKE, Peter. Visto y no visto. El uso de la imagen como documento histórico. Barcelona: Crítica, 2001.

COOK, Nicholas. De Madonna al canto gregoriano. Una muy breve introducción a la música. Madrid: Alianza, 2001. 
ENCABO, Enrique. Art i Humanitats: educar des de la creativitat al segle XXI. Quadern de les idees, les arts i les lletres. Vol. 211, p. 1-8, 2017.

ENCABO, Enrique. El legado de Diaghilev: de los Ballets Rusos a Las zapatillas rojas. En: CHINCHILLA MINGUET, José Luis y DÍAZ OLAYA, Ana María (coord.). Danza, Educación e investigación. Pasado y presente. Málaga: Algibe, 2015, p. 353-360.

FERRER, Antonio. Millennials, la generación del siglo XXI. Nueva Revista de Política, Cultura y Arte, 130, 2010. Disponible en: http://n9.cl/TbV. Acceso: 23 de marzo de 2019.

FLORES AUÑÓN, Juan Carlos. El cine, otro medio didáctico. Introducción a una metodología para el uso del cine como fuente de las Ciencias Sociales. Madrid: Escuela Española, 1982.

FRITH, Simon. La constitución de la música rock como industria transnacional. En: PUIG, Luis y TALENS, Jenaro (eds.). Las culturas del rock. Valencia: Pre-Textos, 1999, p. 11-30.

HUESO, Ángel Luis. El cine y el siglo XX. Barcelona: Ariel, 1998.

MONTOYA RUBIO, Juan Carlos. Música y medios audiovisuales. Planteamientos didácticos en el marco de la Educación Musical (Tesis Doctoral). Salamanca: Servicio de Publicaciones de la Universidad de Salamanca, 2010.

PLANTINGA, León. La música romántica. Madrid: Akal, 1992.

POSTMAN, Neil. Divertirse hasta morir: el discurso público en la era del show business. Barcelona: Ediciones de la Tempestad, 1991.

PRENSKY, Marc. Digital natives, digital immigrants, Part I. On the Horizon. 9 (5), p. 1-6, 2001.

PRENSKY, Marc. Digital natives, digital immigrants, Part II: Do they really think differently?. On the Horizon. 9 (6), p. 1-9, 2001.

SAN CRISTOBAL, Úrsula y LÓPEZ-CANO, Rubén. Ars Video: The Short Music Video in Early and Classical Music. L'ESMUC Digital. Revista de l'Escola Superior de Musica de Catalunya. $\mathrm{N}^{\circ}$ 23, Diciembre 2013. Disponible en: http://www.esmuc.cat/esmuc_digital/Esmucdigital/Revistes/Numero-23-desembre-2013/Espai-de-recerca. Acceso: 23 de marzo de 2019.

SALVÁ, Nando. Vivir a 45 RPM, morir a 24 imágenes por segundo. El biopic rock. En: GUILLOT, Eduardo (coord.). ¡Rock, acción! Ensayos sobre cine y música popular. Valencia: Avantpress Edicions, 2008, p. 167-186. 
SEDEÑO VALDELLÓS, Ana María. El videoclip musical en el contexto del lenguaje audiovisual. En: SÁNCHEZ LÓPEZ, Juan Antonio y GARCÍA GÓMEZ, Francisco (coord.). Historia, estética e iconografía del videoclip musical. Málaga: Universidad de Málaga, 2009, p. 17-42.

SEDEÑO VALDELLÓS, Ana María. Lenguaje del videoclip. Málaga: Universidad de Málaga, Textos mínimos, 2002.

SMALL, Christopher. Música, sociedad, educación. Madrid: Alianza, 1989.

STRANK, Willem. Nuevos medios, nuevos contextos: perspectivas analíticas de la música en la era de Internet. En: ENCABO, Enrique: Música y Cultura Audiovisual: Horizontes. Murcia: Editum, 2014, p. 21-41.

TAGG, Philip. Studying music in the audio-visual media - an epistemological mess, 1995. Disponible en: www.theblackbook.net/acad/tagg/articles. Acceso: 23 de marzo de 2019.

VIÑUELA, Eduardo. El videoclip del siglo XXI: el consumo musical de la televisión a Internet. Musiker: cuadernos de música, $\mathrm{n}^{\circ}$ 20, p. 167-185, 2013.

VIÑUELA, Eduardo. El videoclip como producto de la interacción con otros géneros y medios audiovisuales y lingüísticos. Archivum: Revista de la Facultad de Filología, 52-53, p. 539-550, 2003. 